\title{
A Mixture of Diethylhexyl, Diisononyl and Dibutyl Phthalate Decreased Anogenital Distance, Postnatal Testosterone Levels, and Changed Social Behavior in Wistar Rats
}

\author{
Martina MOROVÁ ${ }^{1}$, Tomáš SENKO ${ }^{1}$, Lucia OLEXOVÁ ${ }^{1}, Z_{\text {Zzana DZIRBÍKOVÁ }}{ }^{1}$, Lucia \\ KRŠKOVÁ ${ }^{1}$
}

${ }^{1}$ Department of Animal Physiology and Ethology, Faculty of Natural Sciences, Comenius

University in Bratislava, Bratislava, Slovak Republic

Received March 30, 2020

Accepted October 6, 2020

\begin{abstract}
Summary
Phthalates are chemicals interfering with the function of testosterone and are suspected to play a role in the emergence of neurodevelopmental diseases. This could be due to interference with brain development for which optimal testosterone levels are essential. We investigated the effect of prenatal and early postnatal exposure to a phthalate mixture on the anogenital distance (AGD), plasma testosterone levels and social behavior in rats. Pregnant rats were exposed to a mixture of diethylhexyl, diisononyl and dibutyl phthalate, each at a dose of $4.5 \mathrm{mg} / \mathrm{kg} /$ day, from gestational day 15 to postnatal day 4 . A social interaction test was performed to assess sociability in the three ontogenetic stages (weaning, puberty, adulthood). AGD was measured in adulthood to assess changes in prenatal testosterone levels. Plasma testosterone levels were measured in adults by a radioimmunoassay. The total frequency and time of socio-cohesive interactions were decreased in phthalate exposed females in weaning, puberty and adulthood. Phthalate exposed males showed a decrease in the frequency of social interactions in weaning only. Shorter anogenital distance was observed in adult males exposed to phthalates. Decreased testosterone levels were observed in the exposed group in both sexes. Our results suggest that early developmental phthalate exposure may play an important role in the hormonal and behavioral changes associated with several neurodevelopmental diseases.
\end{abstract}

\section{Key words}

Phthalate mixture • Testosterone • Anogenital distance • Social behavior $\bullet$ Laboratory rat

\section{Corresponding author}

M. Morová, Department of Animal Physiology and Ethology, Faculty of Natural Sciences, Comenius University in Bratislava, Mlynská dolina, Ilkovičova 6, 84215 Bratislava 4, Slovak Republic. E-mail: morova4@uniba.sk

\section{Introduction}

Phthalates are a large family of ubiquitous environmental pollutants that act as endocrine disruptors - exogenous agents that interfere with the function of natural hormones responsible for the maintenance of homeostasis and the regulation of developmental processes (Kavlock et al. 1996). They are produced in large quantities and widely used to provide flexibility and durability to plastic materials. They also lubricate and act as solvents. They can be found in a wide range of products used in daily life and since there are no covalent bonds between phthalates and the plastics in which they are mixed, they can leach from these products into the environment and enter the body through food consumption, inhalation, dermal contact or intravenous injection (Schettler 2006).

Exposure to endocrine disruptors such as phthalates during fetal and early life is a public health concern because these periods are characterized by high cellular plasticity when the brain is vulnerable to external stimuli. When administered during this crucial time, these chemicals can influence physiology (Kolatorovova et al. 2018), behavior and lead to the development of diseases (Miodovnik et al. 2011). Phthalates can cross the placenta 
(Xu et al. 2008) and have been found in human amniotic fluid (Silva et al. 2004), breast milk (Main et al. 2006) and in young children (Brock et al. 2002).

In rodent models as well as in humans, phthalates downregulate fetal testosterone production and are, therefore, considered anti-androgenic (Barakat et al. 2019, Pallotti et al. 2020) resulting in alterations in reproductive tract development (Repouskou et al. 2019). Prenatal exposure to these chemicals is associated with a decreased anogenital distance (AGD) (Martino-Andrade et al. 2016, Curi et al. 2019) which is related to androgen exposure during fetal development. It was also associated with the neurodevelopmental disability (Whyatt et al. 2012, Kim et al. 2018) and with the modifications of various types of behavior, e.g. sociability impairment (Miodovnik et al. 2011, Lee et al. 2016, Kougias et al. 2018), depression-like behavior (Xu et al. 2015), anxietylike behavior (Carbone et al. 2013, Philippat et al. 2017) and connection has also been made between early developmental phthalate exposure and autism-like behavior in children (Oulhote et al. 2020).

Prenatal testosterone plays a key role in the development of many aspects of mammalian behavior, including anxiety- and depression-like behavior, stress response, and social behavior (Pivina et al. 2007, Hines et al. 2015, Xu et al. 2015). Changes in the levels of testosterone during prenatal development may lead to changes in the programming of the hypothalamicpituitary-adrenal axis (Kapoor and Matthews 2011), that in turn can result in changes in coping strategies in social interaction situation. Individuals prenatally exposed to higher levels of testosterone tend toward a proactive (active) coping strategy, characterized by higher levels of aggression and dominance. In contrast, individuals prenatally exposed to lower levels of testosterone employ reactive strategy (passive), characterized by less aggressive behavior and social avoidance (Koolhaas et al. 1999, Steinman et al. 2017).

In this study, we investigated the effect of prenatal and early postnatal exposure to a mixture of the three most prevalent phthalates (dibutyl phthalate - DBP, diethylhexyl phthalate - DEHP and diisononyl phthalate - DINP) in the environment (Luo et al. 2020) on testosterone levels in adult rats, AGD (a marker of fetal androgen exposure) and the social behavior in weaning, puberty and adulthood. Based on the above information, we hypothesized that there would be decreased serum levels of testosterone in adult offspring, shortened AGD and a decrease in the number and duration of social contacts. This decrease in social behavior would indicate a shift to reactive coping strategies in social interaction situation and would be connected to the decreased level of testosterone during prenatal development.

\section{Methods}

Animal experiments were conducted in accordance with the Principles of Laboratory Animal Care issued by the Ethical Committee of Comenius University in Bratislava, Slovak Republic. The experimental design was approved by the State Veterinary and Food Administration of the Slovak Republic (protocol number: Ro-3726/16-221) and the EU Directive 2010/63/EU for animal experiments was followed.

\section{Animals}

Wistar rats were obtained from the Institute of Experimental Pharmacology and Toxicology, Dobrá Voda, Slovak Republic. The parental generation consisted of 13 females and seven males. Animals were housed in groups of three or four animals in standard light conditions $(12: 12 \mathrm{~h}$ light-dark cycle; light on at 07:00), at an average temperature of $21 \pm 1{ }^{\circ} \mathrm{C}$ and $55 \pm 10 \%$ relative humidity. Water and food (standard laboratory chow, MP-OŠ-06 - Peter Miško, Snina, Slovak Republic) were available ad libitum. After an acclimatization period (7 days), parental animals were tested in an open field test to assess the level of their excitability. Ovulatory cycle phase of female rats was identified according to Gleich and Frohberg (1977). In the evening of the proestrus day, females were housed overnight with males. The presence of spermatozoa in the vaginal smears on the next morning was referred to as gestational day 0 (GD 0).

Pregnant females were divided into two, in terms of excitability balanced groups: control (Ctrl: $n=7)$ and phthalate (Pht: $n=6$ ) and were housed in groups of two or three per cage until GD 20. One day before delivery, Ctrl and Pht females were housed individually and allowed to raise their offspring until weaning at postnatal day (PND) 21. From PND 1 to PND 4, the litters were culled to 8 animals per litter (4 males, 4 females). After weaning, rats of either sex were housed separately in groups of 4 animals per cage.

\section{Treatment}

DEHP, DINP and DBP, $100 \mathrm{mg}$ liquid each were mixed into one solution of $10 \mathrm{ml}$ with peanut oil as 
the vehicle $(10 \mathrm{mg} / \mathrm{ml})$. Solutions were stored at $4{ }^{\circ} \mathrm{C}$ during the experiment. Each morning, from gestational day 15 (GD 15) to PND 4, dams were weighed and the appropriate amount of phthalate, diluted in peanut oil (vehicle), was prepared daily and delivered to each female on a sponge biscuit. Dams from the exposed group received $500 \mu 1$ of the vehicle with an appropriate amount of solution containing DEHP, DBP, and DINP ( $4.5 \mathrm{mg} / \mathrm{kg}$ of each substance). Dams from the Ctrl group received $500 \mu \mathrm{l}$ of the vehicle on a sponge biscuit (adapted from Degroote et al. 2014).

The dose of phthalates used in this study was the same as that reported by Degroote et al. (2014) and was based on their previous work and NOAEL (No Observable Adverse Effect Level) in rats to be well below toxic doses. This dose is still higher than the estimated human exposure (Katsikantami et al. 2016), but since phthalates can act in a dose additive manner (Howdeshell et al. 2015), even smaller doses in combination can cause abnormalities during development.

\section{Social interaction test}

The social interaction test was adapted from File and Hyde (1978). At weaning (PND 21-23), puberty (PND 42-44) and adulthood (PND 77-79), offspring (weaning and puberty - Ctrl: male $n=12$, female $n=12$; Pht: male $n=12$, female $n=12$; adulthood - Ctrl: male $n=12$, female $n=10$; Pht: male $n=10$, female $n=12$ ) were tested for their social behavior with an unknown test partner of the same sex, treatment and approximate weight. Pairs were tested between 16:00 and 19:00. The dimensions of the test box were $72 \times 34 \times 38 \mathrm{~cm}(1 \times \mathrm{w} \times \mathrm{h})$.

Animals were acclimatized to test conditions before the start of testing. Pairs of animals were placed diagonally in the opposite corners of the box. Their behavior was measured for $5 \mathrm{~min}$ and all sessions were recorded using a digital camera (Logitech, Lausanne, SUI). The apparatus was cleaned with water after each test to remove odors of the previous animal.

The total duration and frequency of social interactions (socio-cohesive: following, mutual sniffing, genital investigation, climbing over, crawling under, allogrooming contact, initiation of social play; socioaversive: attack, aggressive unrest, mounting, tail biting, escape, vigilant posture, defense activity) (adapted from Senko et al. 2017) were recorded from the video (for each animal separately) by a trained observer who was blind to the experimental groups.

\section{Anogenital distance}

AGD was measured on male (Ctrl: $n=23$; Pht: $n=23$ ) and female (Ctrl: $n=28$; Pht: $n=22)$ offspring from the center of the anus to the posterior edge of the genital papilla using a digital caliper (Hedue, Mönchengladbach, GER). AGD was measured at PND 82. To increase precision, each animal's AGD was measured three times by the same person; the resulting AGD value is an average of these three measures (adapted from Gallavan et al. 1999).

\section{Testosterone levels}

Blood was collected into heparinized tubes on PND 116-119 (following the decapitation of animals under isoflurane anesthesia). Plasma was separated by centrifugation at $2000 \times \mathrm{g}$ for $10 \mathrm{~min}$, and stored at $-76^{\circ} \mathrm{C}$ until hormone analyses.

Plasma testosterone concentrations were measured by direct radioimmunoassay using $\left[1,2,6,7-^{3} \mathrm{H}\right]$ testosterone tracer (specific activity $95.5 \mathrm{Ci} / \mathrm{mmol}$; PerkinElmer, USA) and a specific antibody generated in rabbits against a testosterone-3-(carboxy-methyl)oxime bovine serum albumin conjugate, following a previously published protocol (Zeman et al. 2016).

We used 5 and $80 \mu 1$ aliquots of plasma for males and females, respectively. Male (Ctrl: $n=15$, Pht: $n=18$ ) and female (Ctrl: $n=26$, Pht: $n=22$ ) samples were run in separate assays, with a mean intra-assay variation coefficient of $7 \%$ and an inter-assay variation coefficient of $8.3 \%$. The assay sensitivity was $1.5 \mathrm{pg}$ of testosterone per tube.

\section{Statistical analysis}

Our data were analysed using SigmaPlot version 11.0 software (SigmaPlot, Systat Software, Inc., Erkrath, GER).

All data were tested for a normal distribution using a Kolmogorov-Smirnov test.

The frequency and time spent in socio-cohesive interactions, AGDs and plasma testosterone concentrations have natural differences between sexes, therefore, the effect of sex was excluded from the analysis. The frequency and time spent in socio-cohesive interactions, AGD and the plasma testosterone concentration were then examined using unpaired Student's $t$-tests (for parametric distributions) or MannWhitney tests (for non-parametric distributions). 


\section{Results}

\section{Social interaction test}

Socio-aversive interactions were rarely observed in weaning and puberty, but we did not find any significant differences between groups (data not shown).

The total frequency of socio-cohesive interactions was decreased in all ontogenetic stages, mostly in females (Fig. 1). In weaning, there was found a significant decrease in Pht males $(\mathrm{t}=-2.251 ; \mathrm{p}<0.05)$ compared to $\mathrm{Ctrl}$ males and also significant decrease in
Pht females $(\mathrm{t}=-2.647 ; \mathrm{p}<0.05)$ compared to Ctrl females. In puberty, there was a significant decrease only in Pht females $(\mathrm{t}=-2.564 ; \mathrm{p}<0.05)$ compared to Ctrl females. In adulthood, Pht females $(\mathrm{t}=-5.228 ; \mathrm{p}<0.001)$ had a significant decrease compared to Ctrl females.

Total time of socio-cohesive interactions was significantly decreased in Pht females compared to Ctrl females (Fig. 2B) in weaning ( $\mathrm{t}=-2.691 ; \mathrm{p}<0.05)$, puberty $(\mathrm{T}=108 ; \mathrm{p}<0.05)$ and adulthood $(\mathrm{t}<-2.385 ; \mathrm{p}<0.001)$. Pht males did not show any significant differences compared to Ctrl males (Fig. 2A).
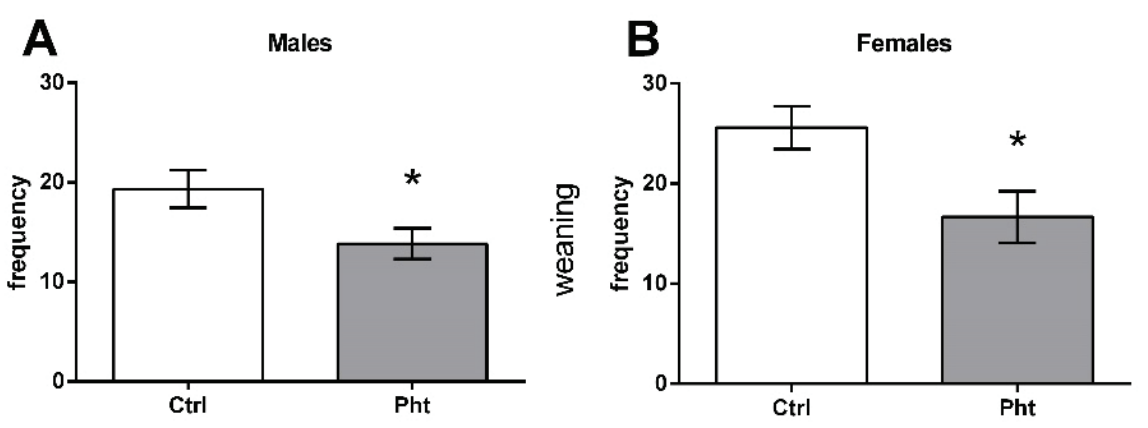

Fig. 1. The total frequency of sociocohesive interactions in control (Ctrl) and phthalate (Pht) males (A) and females (B) in weaning (Pht: male $n=12$, female $n=12$; Ctrl: male $n=12$, female $n=12$ ), puberty (Ctrl: male $n=12$, female $n=12$; Pht: male $n=12$, female $n=12$ ) and adulthood (Ctrl: male $n=12$, female $n=10$; Pht: male $\mathrm{n}=10$, female $\mathrm{n}=12$ ). Data are expressed as mean \pm SEM. Asterisks indicate significant differences $(* p<0.05 ; * * * p<0.001)$.
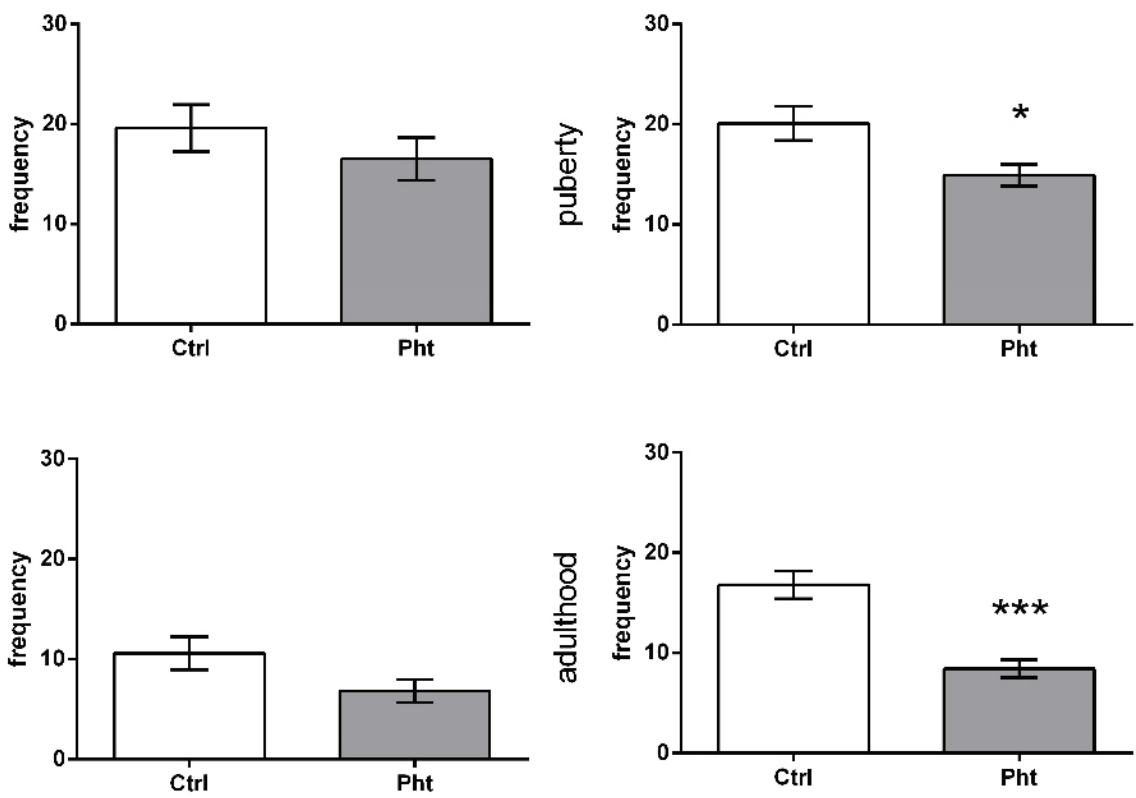

\section{Anogenital distance}

There was a significant decrease in the AGD of males treated with phthalates compared to Ctrl males $(\mathrm{t}=2.047 ; \mathrm{p}<0.05)$ (Fig. 3A). No difference was found between the $\mathrm{Ctrl}$ and $\mathrm{Pht}$ females $(\mathrm{T}=542 ; \mathrm{p}=0.718)$ (Fig. 3B).

\section{Plasma testosterone levels}

Prenatal and early postnatal exposure to phthalates resulted in significantly lower plasma testosterone concentration in males $(\mathrm{t}=2.48 ; \mathrm{p}<0.05)$ (Fig. 4A) and females ( $\mathrm{t}=2.36 ; \mathrm{p}<0.05)$ (Fig. 4B).

\section{Discussion}

There has been growing evidence supporting the role of phthalates in the etiology of neurodevelopmental diseases (Jeddi et al. 2016). The exact mechanisms are 
still not elucidated, but there seems to be a connection with changes in the prenatal levels of testosterone, a hormone important not only in brain development (Negri-Cesi et al. 2004) but also in the development of social behavior (Knickmeyer et al. 2005) and affected by phthalate exposure (Barakat et al. 2019, Pallotti et al.
2020). Therefore, in our study we examined the effect of prenatal and early postnatal exposure to a mixture of most widely used phthalates on the social behavior of laboratory rats and the anti-androgenic effect of these substances, evaluated here as the AGD and postnatal plasma testosterone levels.
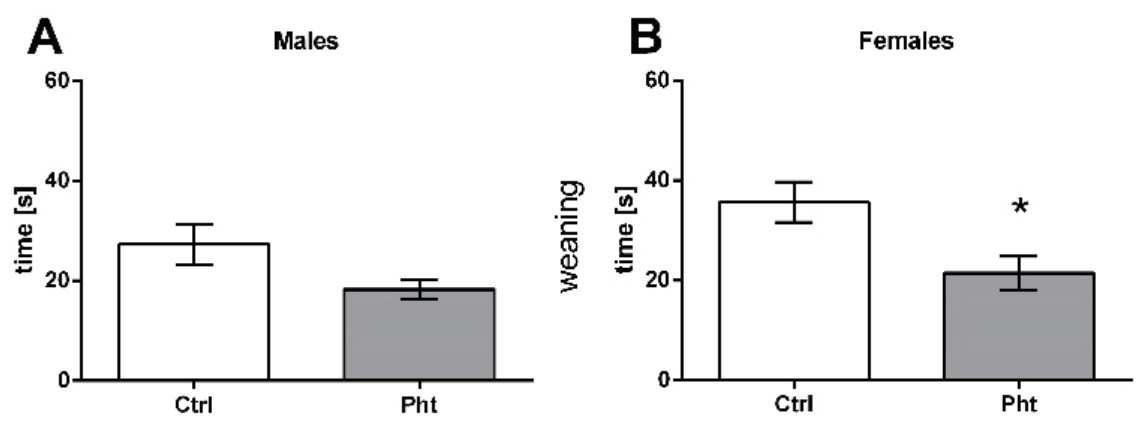

Fig. 2. The total time spent in sociocohesive interactions in control (Ctrl) and phthalate (Pht) males (A) and females (B) in weaning (Pht: male $n=12$, female $n=12 ;$ Ctrl: male $n=12$, female $n=12$ ), puberty (Ctrl: male $n=12$, female $n=12$; Pht: male $n=12$, female $n=12$ ) and adulthood (Ctrl: male $n=12$, female $n=10$; Pht: male $\mathrm{n}=10$, female $\mathrm{n}=12$ ). Data are expressed as mean \pm SEM. Asterisks indicate significant differences $(* p<0.05 ; * * * p<0.001)$.
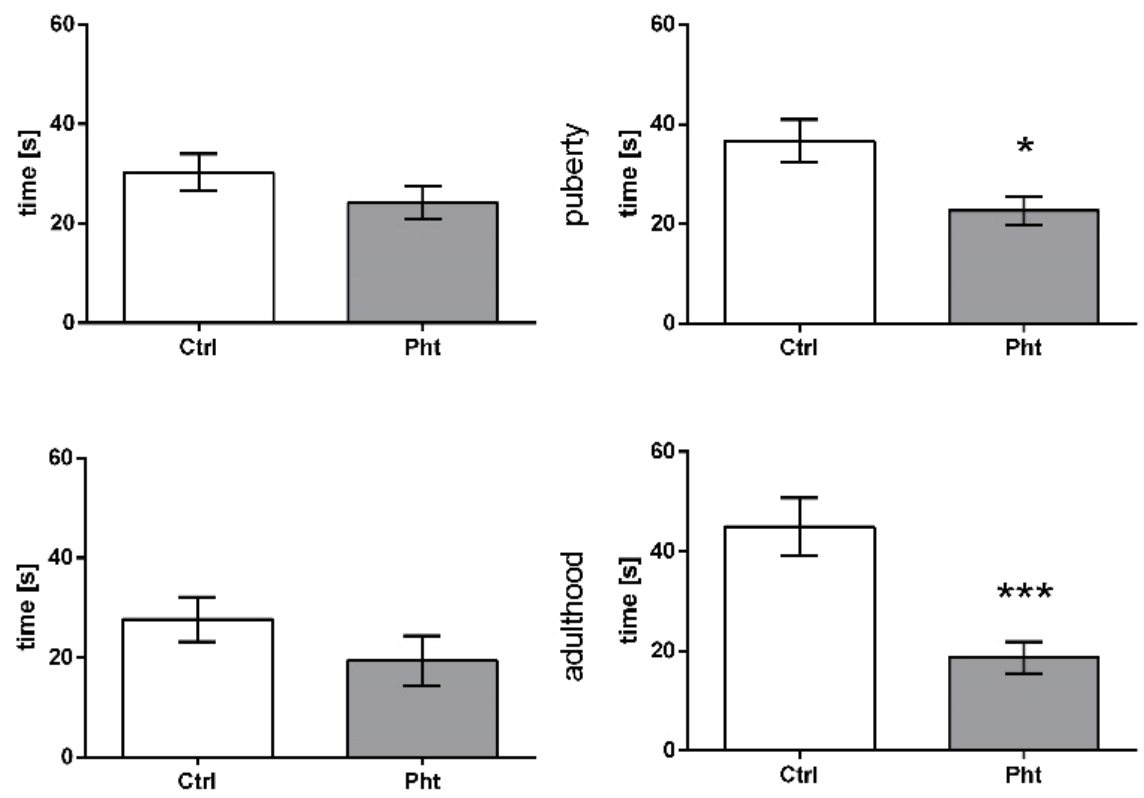

We observed, that Pht females had less sociocohesive interactions in weaning, puberty and adulthood, both in terms of frequency and time compared to Ctrl females. Pht males had a lower frequency of sociocohesive interactions in weaning compared to control males. AGD was affected only in males, with Pht males having shortened AGD. Plasma testosterone levels were lower in both males and females exposed to a phthalate mixture of DEHP, DBP and DINP.

In a study by Degroote et al. (2014), rats (PND 40) that were prenatally exposed to a mixture of endocrine disruptors, including phthalates, showed impaired social behavior. Males spent less time in social interactions, and in both sexes, escaping behavior was observed during the social interaction test. The authors speculated that this behavior could indicate higher social avoidance. Lee et al. (2016) found that maternal DEHP exposure induced a deficit in social interactions of mice offspring (PND 56) and in a study by Quinnies et al. (2017) socially investigative behaviors were reduced in mice (PND 28-32) prenatally exposed to DEHP.

In women, metabolites of phthalates during gestation were associated with greater social deficits in their children (aged 7-9) (Miodovnik et al. 2011). Whyatt et al. (2012) and Philippat et al. (2017) found positive associations between prenatal phthalate metabolites and the internalizing behavior of boys (aged 3). In a study by Won et al. (2016), in which the neurobehavioral 
development of children (aged 6-18) was assessed, there was a significant association between phthalates measured in children's urine and social problems in younger children (aged 6-11), who showed greater vulnerability to phthalate exposure.
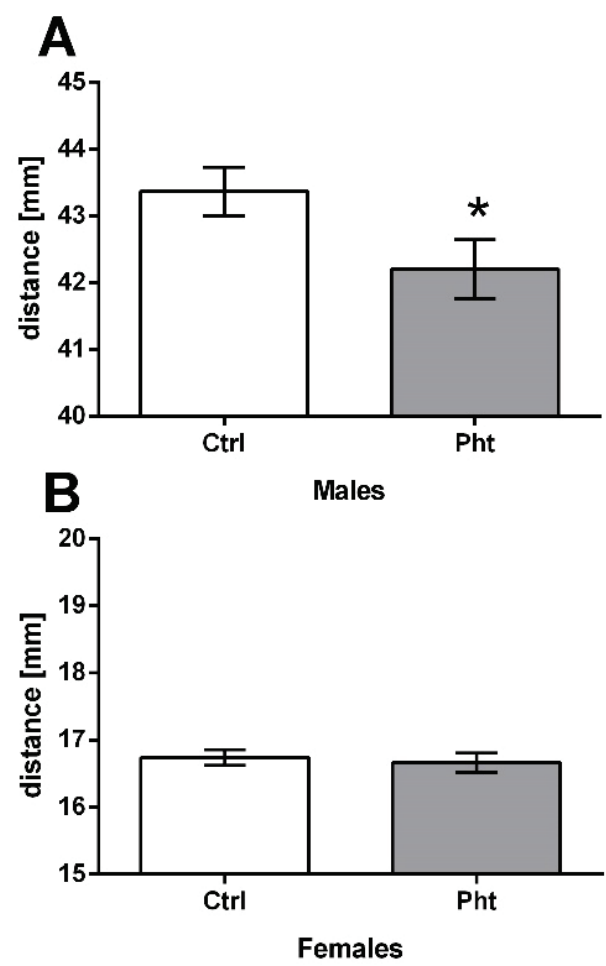

Fig. 3. Anogenital distance in control (Ctrl: $n=23)$ and phthalate (Pht: $\mathrm{n}=23$ ) males (A) and anogenital distance in control (Ctrl: $n=28$ ) and phthalate (Pht: $n=22$ ) females (B). Data are expressed as mean \pm SEM. Asterisk indicates significant differences between groups $(* p<0.05)$.

In the most studies mentioned above, social behavior was investigated in the earlier stages of postnatal development. In our study, we examined this behavior from weaning to adulthood and our findings, together with those of other authors, could support a possible role of phthalate exposure in the development of behavioral problems which last from early stages of postnatal development to adulthood.

Changes in behavior are believed to be the consequence of disruption in neurodevelopment, as the brain is the organ controlling behavior and is highly vulnerable to disruption due to exogenous agents during the critical phases of its development (Schug et al. 2015). In their studies, Miodovnik et al. (2011) and Whyatt et al. (2012) discuss the possible role of phthalates in influencing prenatal levels of thyroid and sex hormones, whose importance for brain development have been well described (Bernal 2005, Schwarz and McCarthy 2008).
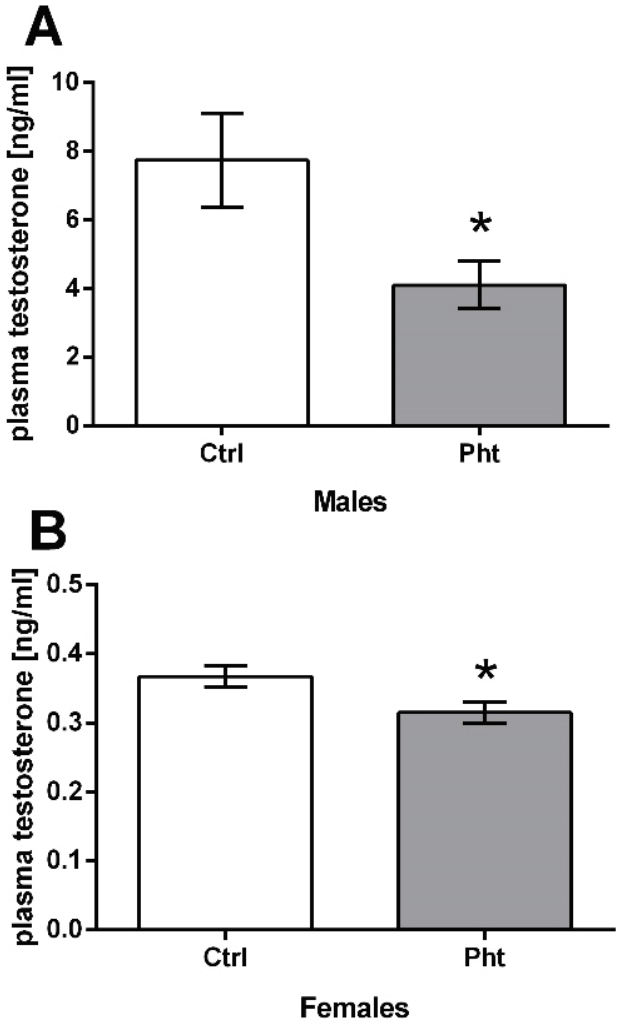

Fig. 4. The plasma testosterone concentration in control (Ctrl: $n=15$ ) and phthalate (Pht: $n=18$ ) males (A) and in control (Ctrl: $n=26$ ) and phthalate (Pht: $n=22$ ) females (B). Data are expressed as mean $\pm \mathrm{SEM}$. Asterisk indicates significant differences between groups $(* p<0.05)$.

In regard to this, we focus our research on the relationship between phthalates, testosterone production and changes in behavior due to changes in the brain. The importance of the testosterone-brain-behavior relationship was confirmed by our previous study (Dzirbíková et al. 2018) and considering these and previous results we propose yet another possible explanation for observed changes in social behavior.

If we apply Koolhaas's model (Koolhaas et al. 1999) of coping style on our data, we see that animals from Pht group seem to be more reactive (passive) in social interaction with an unknown rat. Reactive coping is associated with lower testosterone activity. We found that phthalate-affected individuals have lower testosterone levels, and this, together with our behavioral data, suggest a shift to reactive coping. The fact that prenatal testosterone plays an important role in the programming of postnatal strategies is also confirmed by our previous study. We found that testosterone application during the last third of pregnancy had an impact on social coping in social interaction test and caused a shift to proactivity (more time spent in social interaction) (Dzirbíková et al. 2018). 
In our study, a decrease in social behavior in the Pht group was noticeable in both sexes but was more pronounced in females. This could mean that males and females react differently under the influence of exposure to prenatal phthalates, which was also suggested by other authors (Whyatt et al. 2012, Degroote et al. 2014, Won et al. 2016). It seems that further studies will be required to thoroughly evaluate the effect of phthalates on behavior in both sexes.

There is no doubt that phthalates are endocrine disruptors with anti-androgenic properties (Barakat et al. 2019, Pallotti et al. 2020). In our study, we detected a decrease in plasma testosterone levels in male and female adult rats after phthalate exposure. This long-term decrease in testosterone levels could indicate a decrease in its production. Many studies have described the damage to the reproductive system after prenatal phthalate exposure, including a decrease in testosterone production (Barakat et al. 2019, Repouskou et al. 2019).

AGD is determined prenatally by the testosterone metabolite, dihydrotestosterone, therefore, can be used as a marker for a decrease in the prenatal levels of testosterone (Swan et al. 2005). We observed shortened AGDs, which is consistent with reduced testosterone levels. In our study, only males had a reduced AGD. This result is in accordance with previous studies conducted on laboratory rodents (Parks et al. 2000, Wang et al. 2016) and could be related to the fact that reproductive tract masculinization is hormone-dependent, while development of the female reproductive tract proceeds without any specific interventions (Sharpe 2006).

There have been previous studies of laboratory animals prenatally exposed to lower doses of phthalates, which have also observed a negative effect on testosterone production and social behavior (Degroote et al. 2014, Sekaran and Jagadeesan 2015). Nonetheless, this is (to the best of our knowledge) the first study in which exposure to a mixture of phthalates at a relatively low dose during prenatal and early postnatal development had an observed effect on behavior and testosterone production in adulthood.

\section{Conclusions}

Our results regarding decreased social behavior are consistent with studies in human population indicating significant impacts of early life exposure to phthalates on behavioral outcomes. Changes in behavioral settings may be related to the fact that phthalates alter the levels of testosterone. Testosterone determines brain development and contributes to the formation of a coping strategy in social interactions. A decrease in its levels could therefore initiate a shift to the reactive coping strategy and lead to the decrease of social behavior. This could suggest a role of prenatal phthalate exposure in behavioral programming and a role in the emergence of neurodevelopmental diseases.

\section{Conflict of Interest}

There is no conflict of interest.

\section{Acknowledgements}

The authors would like to thank Assoc. prof. Monika Okuliarová for her help with radioimmunoassay and statistical analysis, and MSc. Eva Šimončičová for her assistance with behavioral data collecting. This work was supported by grants VEGA 2/0166/16 and UK/73/2018.

\section{References}

BARAKAT R, SEYMORE T, LIN PP, PARK CJ, KO CJ: Prenatal exposure to an environmentally relevant phthalate mixture disrupts testicular steroidogenesis in adult male mice. Environ Res 172: 194-201, 2019. https://doi.org/10.1016/j.envres.2019.02.017

BERNAL J: Thyroid hormones and brain development. Vitam Horm 71: 95-122, 2005. https://doi.org/10.1016/S00836729(05)71004-9

BROCK JW, CAUDILL SP, SILVA MJ, NEEDHAM LL, HILBORN ED: Phthalate monoesters levels in the urine of young children. Bull Environ Contam Toxicol 68: 309-314, 2002. https://doi.org/10.1007/s001280255

CARBONE S, PONZO OJ, GOBETTO N, SAMANIEGO YA, REYNOSO R, SCACCHI P, MOGUILEVSKY JA, CUTRERA R: Antiandrogenic effect of perinatal exposure to the endocrine disruptor di-(2-ethylhexyl) phthalate increases anxiety-like behavior in male rats during sexual maturation. Horm Behav 63: 692-699, 2013. https://doi.org/10.1016/j.yhbeh.2013.01.006 
CURI TZ, DA SILVA GN, PASSONI MT, LIMA TOLOUEI SE, MELDOLA H, ROMANO RM, GRECHI N, DALSENTER PR, MARTINO-ANDRADE AJ: In utero and lactational exposure to diisopentyl phthalate (DiPeP) induces fetal toxicity and antiandrogenic effects in rats. Toxicol Sci 2019: kfz159, 2019. https://doi.org/10.1093/toxsci/kfz159

DEGROOTE S, HUNTING D, SÉBIRE G, TAKSER L: Autistic-like traits in Lewis rats exposed perinatally to a mixture of common endocrine disruptors. Endocr Disr 2: e976123, 2014. https://doi.org/10.4161/23273747.2014.976123

DZIRBÍKOVÁ Z, TALAROVIČOVÁ A, ŠTEFÁNIK P, OLEXOVÁ L, KRŠKOVÁ L: Testosterone enhancement during pregnancy influences social coping and gene expression of oxytocin and vasopressin in the brain of adult rats. Acta Neurobiol Exp (Wars) 78: 264-270, 2018. https://doi.org/10.21307/ane-2018-024

FILE SE, HYDE JR: Can social interaction be used to measure anxiety? Br J Pharmacol 62: 19-24, 1978. https://doi.org/10.1111/j.1476-5381.1978.tb07001.x

GALLAVAN RH, HOLSON JF, STUMP DG, KNAPP JF, REYNOLDS VL: Interpreting the toxicologic significance of alterations in anogenital distance: potential for confounding effects of progeny body weights. Reprod Toxicol 13: 383-390, 1999. https://doi.org/10.1016/S0890-6238(99)00036-2

GLEICH J, FROHBERG H: An introduction to research techniques. In: Methods in Prenatal Toxicology. Evaluation of Embryotoxics Effects in Experimental Animal. NEUBERT D. (ed.), PSG Publishing Co, Stuttgart, 1977, pp 94-102.

HINES M, CONSTANTINESCU M, SPENCER D: Early androgen exposure and human gender development. Biol Sex Differ 6: 3, 2015. https://doi.org/10.1186/s13293-015-0022-1

HOWDESHELL KL, RIDER CV, WILSON VS, FURR JR, LAMBRIGHT CR, GRAY LE JR: Dose addition models based on biologically relevant reductions in fetal testosterone accurately predict postnatal reproductive tract alterations by a phthalate mixture in rats. Toxicol Sci 148: 488-502, 2015. https://doi.org/10.1093/toxsci/kfv196

JEDDI MZ, JANANI L, MEMARI AH, AKHONDZADEH S, YUNESIAN M: The role of phthalate esters in autism development: A systematic review. Environ Res 151: 493-504, 2016. https://doi.org/10.1016/j.envres.2016.08.021

KAPOOR A, MATTHEWS SG: Testosterone is involved in mediating the effects of prenatal stress in male guinea pig offspring. J Physiol 589: 755-766, 2011. https://doi.org/10.1113/jphysiol.2010.200543

KATSIKANTAMI I, SIFAKIS S, TZATZARAKIS MN, VAKONAKI E, KALANTZI OI, TSATSAKIS AM, RIZOS AK: A global assessment of phthalates burden and related links to health effects. Environ Int 97: 212-236, 2016. https://doi.org/10.1016/j.envint.2016.09.013

KAVLOCK RJ, DASTON GP, DEROSA C, FENNER-CRISP P, GRAY LE, KAATTARI S, LUCIER G, LUSTER M, MAC MJ, MACZKA C, MILLER R, MOORE J, ROLLAND R, SCOTT G, SHEEHAN DM, SINKS T, TILSON HA: Research needs for the risk assessment of health and environmental effects of endocrine disruptors: a report of the U.S. EPA-sponsored workshop. Environ Health Perspect 104: 715-740, 1996. https://doi.org/10.1289/ehp.96104s4715

KIM S, EOM S, KIM HJ, LEE JJ, CHOI G, CHOI S, KIM S, KIM SY, CHO G, KIM YD, SUH E, KIM SK, KIM S, KIM GH, MOON HB, PARK J, KIM S, CHOI K, EUN SH: Association between maternal exposure to major phthalates, heavy metals, and persistent organic pollutants, and the neurodevelopmental performances of their children at 1 to 2years of age- CHECK cohort study. Sci Total Environ 624: 377-384, 2018. https://doi.org/10.1016/j.scitotenv.2017.12.058

KNICKMEYER R, BARON-COHEN S, RAGGATT P, TAYLOR K: Foetal testosterone, social relationships, and restricted interests in children. J Child Psychol Psychiatry 46: 198-210, 2005. https://doi.org/10.1111/j.14697610.2004.00349.x

KOLATOROVA L, VITKU J, VAVROUS A, HAMPL R, ADAMCOVA K, SIMKOVA M, PARIZEK A, STARKA L, DUSKOVA M: Phthalate metabolites in maternal and cord plasma and their relations to other selected endocrine disruptors and steroids. Physiol Res 67 (Suppl 3): S473-S487, 2018. https://doi.org/10.33549/physiolres.933962

KOOLHAAS JM, KORTE SM, DE BOER SF, VAN DER VEGT BJ, VAN REENEN CG, HOPSTER H, DE JONG IC, RUIS MA, BLOKHUIS HJ: Coping styles in animals: current status in behavior and stress-physiology. Neurosci Biobehav Rev 23: 925-935, 1999. https://doi.org/10.1016/S0149-7634(99)00026-3 
KOUGIAS DG, CORTES LR, MOODY L, RHOADS S, PAN YX, JURASKA JM: Effects of perinatal exposure to phthalates and a high-fat diet on maternal behavior and pup development and social play. Endocrinology 159: 1088-1105, 2018. https://doi.org/10.1210/en.2017-03047

LEE KI, CHIANG CW, LIN HC, ZHAO JF, LI CT, SHYUE SK, LEE TS: Maternal exposure to di-(2-ethylhexyl) phthalate exposure deregulates blood pressure, adiposity, cholesterol metabolism and social interaction in mouse offspring. Arch Toxicol 90: 1211-1224, 2016. https://doi.org/10.1007/s00204-015-1539-0

LUO Q, LIU ZH, YIN H, DANG Z, WU PX, ZHU NW, LIN Z, LIU Y: Global review of phthalates in edible oil: An emerging and nonnegligible exposure source to human. Sci Total Environ 704: 135369, 2020. https://doi.org/10.1016/j.scitotenv.2019.135369

MAIN KM, MORTENSEN GK, KALEVA MM, BOISEN KA, DAMGAARD IN, CHELLAKOOTY M, SCHMIDT IM, SUOMI AM, VIRTANEN HE, PETERSEN DV, ANDERSSON AM, TOPPARI J, SKAKKEBAEK NE: Human breast milk contamination with phthalates and alterations of endogenous reproductive hormones in infants three months of age. Environ Health Perspect 114: 270-276, 2006. https://doi.org/10.1289/ehp.8075

MARTINO-ANDRADE AJ, LIU F, SATHYANARAYANA S, BARRETT ES, REDMON JB, NGUYEN RH, LEVINE H, SWAN SH, TIDES STUDY TEAM: Timing of prenatal phthalate exposure in relation to genital endpoints in male newborns. Andrology 4: 585-593, 2016. https://doi.org/10.1111/andr.12180

MIODOVNIK A, ENGEL SM, ZHU C, YE X, SOORYA LV, SILVA MJ, CALAFAT AM, WOLFF MS: Endocrine disruptors and childhood social impairment. Neurotoxicology 32: 261-267, 2011. https://doi.org/10.1016/j.neuro.2010.12.009

NEGRI-CESI P, COLCIAGO A, CELOTTI F, MOTTA M: Sexual differentiation of the brain: role of testosterone and its active metabolites. J Endocrinol Invest 27: 120-127, 2004.

OULHOTE Y, LANPHEAR B, BRAUN JM, WEBSTER GM, ARBUCKLE TE, ETZEL T, FORGET-DUBOIS N, SEGUIN JR, BOUCHARD MF, MACFARLANE A, OUELLET E, FRASER W, MUCKLE G: Gestational exposures to phthalates and folic acid, and autistic traits in Canadian children. Environ Health Perspect 128: 27004, 2020. https://doi.org/10.1289/EHP5621

PALLOTTI F, PELLONI M, GIANFRILLI D, LENZI A, LOMBARDO F, PAOLI D: Mechanisms of testicular disruption from exposure to bisphenol A and phtalates. J Clin Med 9: 471, 2020. https://doi.org/10.3390/jcm9020471

PARKS LG, OSTBY JS, LAMBRIGHT CR, ABBOTT BD, KLINEFELTER GR, BARLOW NJ, GRAY LE JR: The plasticizer diethylhexyl phthalate induces malformations by decreasing fetal testosterone synthesis during sexual differentiation in the male rat. Toxicol Sci 58: 339-349, 2000. https://doi.org/10.1093/toxsci/58.2.339

PHILIPPAT C, NAKIWALA D, CALAFAT AM, BOTTON J, DE AGOSTINI M, HEUDE B, SLAMA R, EDEN MOTHER-CHILD STUDY GROUP: Prenatal exposure to nonpersistent endocrine disruptors and behavior in boys at 3 and 5 years. Environ Health Perspect 125: 097014, 2017. https://doi.org/10.1289/EHP1314

PIVINA SG, AKULOVA VK, ORDYAN NE: Characteristics of behavior and stress reactivity of the hypophysealadrenocortical system in rats with prenatal inhibition of testosterone metabolism. Neurosci Behav Physiol 37 : 53-58, 2007. https://doi.org/10.1007/s11055-007-0149-6

QUINNIES KM, HARRIS EP, SNYDER RW, SUMNER SS, RISSMAN EF: Direct and transgenerational effects of low doses of perinatal di-(2-ethylhexyl) phthalate (DEHP) on social behaviors in mice. PLoS One 12: e0171977, 2017. https://doi.org/10.1371/journal.pone.0171977

REPOUSKOU A, PANAGIOTIDOU E, PANAGOPOULOU L, BISTING PL, TUCK AR, SJÖDIN MOD, LINDBERG J, BOZAS E, RÜEGG J, GENNINGS C, BORNEHAG CG, DAMDIMOPOULOU P, STAMATAKIS A, KITRAKI E: Gestational exposure to an epidemiologically defined mixture of phthalates leads to gonadal dysfunction in mouse offspring of both sexes. Sci Rep 9: 6424, 2019. https://doi.org/10.1038/s41598-019-42377-6

SEKARAN S, JAGADEESAN A: In utero exposure to phthalate downregulates critical genes in Leydig cells of F1 male progeny. J Cell Biochem 116: 1466-1477, 2015. https://doi.org/10.1002/jcb.25108

SENKO T, SVITOK P, KRŠKOVÁ L: Effect of maternal renin-angiotensin-aldosterone system activation on social coping strategies and gene expression of oxytocin and vasopressin in the brain of rat offspring in adulthood. Gen Physiol Biophys 36: 391-398, 2017. https://doi.org/10.4149/gpb_2017013

SHARPE RM: Pathways of endocrine disruption during male sexual differentiation and masculinization. Best Pract Res Clin Endocrinol Metab 20: 91-110, 2006. https://doi.org/10.1016/j.beem.2005.09.005 
SCHETTLER T: Human exposure to phthalates via consumer products. Int J Androl 29: 134-139; discussion 181-185, 2006. https://doi.org/10.1111/j.1365-2605.2005.00567.x

SCHUG TT, BLAWAS AM, GRAY K, HEINDEL JJ, LAWLER CP: Elucidating the links between endocrine disruptors and neurodevelopment. Endocrinology 156: 1941-1951, 2015. https://doi.org/10.1210/en.2014-1734

SCHWARZ JM, MCCARTHY MM: Steroid-induced sexual differentiation of the developing brain: multiple pathways, one goal. J Neurochem 105: 1561-1572, 2008. https://doi.org/10.1111/j.1471-4159.2008.05384.x

SILVA MJ, REIDY JA, HERBERT AR, PREAU JL JR, NEEDHAM LL, CALAFAT AM: Detection of phthalate metabolites in human amniotic fluid. Bull Environ Contam Toxicol 72: 1226-1231, 2004. https://doi.org/10.1007/s00128-004-0374-4

STEINMAN MQ, TRAINOR BC: Sex differences in the effects of social defeat on brain and behavior in the California mouse: Insights from a monogamous rodent. Semin Cell Dev Biol 61: 92-98, 2017. https://doi.org/10.1016/j.semcdb.2016.06.021

SWAN SH, MAIN KM, LIU F, STEWART SL, KRUSE RL, CALAFAT AM, MAO CS, REDMON JB, TERNAND CL, SULLIVAN S, TEAGUE JL, STUDY FOR FUTURE FAMILIES RESEARCH TEAM: Decrease in anogenital distance among male infants with prenatal phthalate exposure. Environ Health Perspect 113: 1056-1061, 2005. https://doi.org/10.1289/ehp.8100

WANG R, XU X, WENG H, YAN S, SUN Y: Effects of early pubertal exposure to di-(2-ethylhexyl) phthalate on social behavior of mice. Horm Behav 80: 117-124, 2016. https://doi.org/10.1016/j.yhbeh.2016.01.012

WHYATT RM, LIU X, RAUH VA, CALAFAT AM, JUST AC, HOEPNER L, DIAZ D, QUINN J, ADIBI J, PERERA FP, FACTOR-LITVAK P: Maternal prenatal urinary phthalate metabolite concentrations and child mental, psychomotor and behavioral development at 3years of age. Environ Health Perspect 120: 290-295, 2012. https://doi.org/10.1289/ehp.1103705

WON EK, KIM Y, HA M, BURM E, KIM YS, LIM H, JUNG DE, LIM S, KIM SY, KIM YM, KIM HC, LEE KJ, CHEONG HK, KANG HT, SON M, SAKONG J, OH GJ, LEE CG, KIM SY, RYU JM, KIM SJ: Association of current phthalate exposure with neurobehavioral development in a national sample. Int J Hyg Environ Health 219: 364-371, 2016. https://doi.org/10.1016/j.ijheh.2016.03.001

XU X, YANG Y, WANG R, WANG Y, RUAN Q, LU Y: Perinatal exposure to di-(2-ethylhexyl) phthalate affects anxiety- and depression-like behaviors in mice. Chemosphere 124: 22-31, 2015. https://doi.org/10.1016/j.chemosphere.2014.10.056

XU Y, AGRAWAL S, COOK TJ, KNIPP GT: Maternal di-(2-ethylhexyl)-phthalate exposure influences essential fatty acid homeostasis in rat placenta. Placenta 29: 962-969, 2008. https://doi.org/10.1016/j.placenta.2008.08.011

ZEMAN M, MOLČAN L, OKULIAROVÁ M, HERICHOVÁ I: Endocrine and cardiovascular rhythms differentially adapt to chronic phase-delay shifts in rats. Chronobiol Int 33: 1148-1160, 2016. https://doi.org/10.1080/07420528.2016.1203332 